Factors Affecting Academic Performance of International students in Project Management Courses: A Case Study from a British Post 92 University.

R M Lebcir ${ }^{1}$,Wells $\mathrm{H}^{1}$, Bond $\mathrm{A}^{1}$

1 The Business School, University of Hertfordshire, College Lane, Hatfield AL10 9AB

Correspondence: Dr Read M LEBCIR

Senior Lecturer

The Business School

University of Hertfordshire

College Lane, Hatfield

AL10 9AB

Tel: ++.44(0)1707.285504

Fax: ++.44(0)1707.285410

Email: M.R.Lebcir@Herts.ac.uk 


\title{
Factors Affecting Academic Performance of International students in Project Management Courses: A Case Study from a British Post 92 University.
}

\begin{abstract}
The aim of study is to investigate the factors affecting the academic performance of international students in Project Management courses. To achieve this aim, a conceptual framework including three categories of factors: (i) Teaching Style, (ii) English Language and Communication and (iii) Assessment Methods was developed and empirically tested on a sample of international students from a British Post 92 University.

The results suggest that the factors: level of details given in lectures, speed of lectures, academic internet sources, English Language skills, group or individual assessment, the qualitative/quantitative content of assessment are important drivers of the academic performance of international students in Project Management.
\end{abstract}

Keywords: Project Management, Higher Education, International Students, Academic Performance, Teaching and Learning. 


\section{Factors Affecting Academic Performance of International students in Project Management Courses: A Case Study from a British Post 92 University.}

\section{Introduction}

International students constitute an important part of university life in the United Kingdom. Most universities in the UK have a considerable fraction of their students from overseas and this has many advantages. It makes the university vibrant, enables contact, understanding, and shared experiences between students from different cultural and ethnic backgrounds, and allows university staff to broaden their knowledge about the education systems in different countries.

In addition, international students contribute significantly to the financial resources of universities through full payment of the education costs. In this context and given the ever growing competition between different parts of the world (United States, Europe, Australia) to attract these international students, it is vital and crucial that UK universities offer the best possible educational experience for these students to ensure that universities do not lose their competitive advantage to other parts of the world.

The aim of this paper is to investigate an important area of the education of international students, that is, their academic performance in UK universities. Because the experience of the authors is in teaching Project Management courses, we would like to investigate the factors affecting the academic performance of international students in Project Management modules at undergraduate and postgraduate levels. Academic performance, in this case, means the general level of grades in exams, course-works, and dissertations.

Although, our observations suggest that international students tend not to do well in some Project Management modules, it is important that the issue of international students' 
academic performance is formally investigated and its underlying factors determined and addressed.

Perhaps unsurprisingly we found no existing research on the academic performance of international students in project management. The literature that does exist on learning, teaching and assessment in project management is quite limited and focuses mainly on the issues regarding the topics, which should be included in the teaching of the subject and how these topics should be taught and assessed [1]

To overcome this lack of research in this area and fill this gap, the aim of this paper is to identify whether aspects of the project management subject or aspects of learning, teaching and assessment may indicate a potential reason to explain the academic performance of international students.

The paper is organised as follows. The first section presents a literature review of previous research in the area of academic performance. This is followed by a presentation of the research methodology and the process of data gathering. The results are then presented and discussed. The paper concludes by a summary of the main findings and identification of potential routes for further research.

\section{Literature Review}

Morrison [2] highlights some of the different definitions of international students. Our definition is broad, to encompass all students for whom English is not their first language and/or those who may not have studied in the British or higher education systems in which English is the main language of studies. Thus we include European Union (EU) students who, according to fee status definitions, would otherwise be considered 'home' students. 
Few articles or texts on international students (generally studying in UK, US or Australian higher education institutes) relate to academic performance. More commonly covered are the student experience [3], matters of cross-cultural adjustment, the 'deficits' in language or academic skills, institutional support [4], and guidance for tutors or students preparing to study in western institutions in which English is the main language of study ([5],[6],[7]).

Much of the work takes a problematical view of international students in higher education, focusing on the deficits and how these might be remedied. In this context, Biggs [8] argues that the 'deficit approach' (responding to what international students are deemed to lack and what home students are assumed to possess) arises from certain perspectives on teaching, namely assimilating and accommodating student differences. However, a 'contextual', flexible approach, emerges from 'aligned teaching' ${ }^{\mathrm{i}}$ and the premise that whilst international students may experience difficulty with matters of teaching, they are not necessarily different to those experienced by other students. Therefore 'good' learning strategies and teaching practice benefit all students. These conclusions draw on studies by Volet [9] and Mullins [10] and are demonstrated implicitly in recommendations on specific learning, teaching and assessment techniques.

Similarly, De Vita [11] makes recommendations for inclusive approaches and adapting teaching style to learning style in the multi-cultural classroom [11]. Practices such as making material available in visual form and enabling students to read before and/or reflect after lectures are often recommended to support international students.

i The alignment of 'Presage' factors (the learning context and student-level factors that precede the learning process), 'Process' (activities that should promote 'deep' learning) and Product (learning outcomes, whether qualitative, quantitative or affective). See Biggs [8] 3Ps model, page 19. 
The few studies on the performance of international students demonstrate the complexity of factors involved and that views cannot be generalised. For example, the UK national study by Morrison [2] found that overall, international-domiciled students achieved fewer first class or upper second class honours degrees than did UK-domiciled students and, in multi-level analysis, identified variations by region, country of origin, discipline, and qualifications on entry ([3], [12], [13], [14], [15], [16], [17], [18], [19]).

To seek explanations for the academic performance of international students, we reviewed literature on the factors that influence academic success (whether measured in terms of grades and awards achieved or progression). We found that contemporary texts on teaching and learning in higher education (for example [8] and [20]) are based on constructivist approaches and student learning and teaching approaches that encourage 'deep' learning $[21]^{\mathrm{ii}}$. However, this literature is general in nature and does not differentiate explicitly between international and home students on the approaches that lead to academic success. The same can be said about some of the factors that are considered to be an indicator of performance, such as preentry qualifications (excluding Test of English as a Foreign Language, TOEFL, or similar).

Other factors found to have impact on academic performance of international students relate to the English language skills of these students. Although many universities set a minimum standard of English for international students and the great majority offer language support, (pre-session and/or in-session [4]), language is still experienced as an issue by lecturers. Language cannot be addressed simplistically. Cammish [24] identifies the difficulty in separating language from culture (as does Todd [25]) and differentiates between the

\footnotetext{
ii 'Learning approach' is the term generally accepted to describe the "qualitative approaches in how students respond to a learning task." (Marton [22] cited in [23]) and includes both the students' intention and process of learning. A 'deep' learning approach is more likely to elicit a higher level of understanding than a 'surface' approach. Byrne[23] also identifies a strategic approach, where students adopt a strategy appropriate to achieving high grades and the ASSIST inventory identifies the instrumental approach (apathetic to the surface approach).
} 
difficulties faced by international students in four language skills (listening, speaking, reading and writing).

Adjustment to a new academic environment and culture has also been highlighted by a number of writers. Cortazzi [26] discuss learning to communicate across academic cultures, cultures of communication, and cultures of learning. Ridley [27] suggests that whilst all students entering higher education may be confused by the academic discourse of particular disciplines this can be of particular concern to students "who have not had language, literacy, and learning experiences" similar to those who have been prepared to enter higher education. In addressing written assignments in particular, she identifies specific gaps in expectations between international students and academic tutors and how they may be addressed.

Another stream of research on teaching, learning and assessment indicates that some activities may be disadvantageous, or of lower preference, to international students, for example notetaking in lectures ([28], [29]). De Vita [30] explored the cultural equivalence properties of commonly adopted assessment methods and found that assessment by examination penalises international students beyond differences in ability levels, as measured by multiple-choice test and coursework assignment scores. In one US university ratings by students from cultures preferring techniques where the instructor provides high structure differed slightly from the ratings by students from cultures preferring techniques where the instructor provides lower structure [31].

In addressing specific academic skills a number of cases highlight the adaptability of international students. When setting a critical thinking task in macroeconomics, Jones [32] concluded that cultural and linguistic differences are important to the way learning, teaching and assessment activities are presented. Adams [33] conducted an experiment in Australia and found that lecturers' close interaction with international students during tutorials and seminars had a positive impact on their academic performance. 
Therefore, the factors impacting the academic performance of international students in Project Management can be summarised into a conceptual model, which include three categories of factors: (i) Teaching style, (ii) English Language and Communication, and (iii) Assessment Methods (See Figure 1). This framework is tested, through the design and statistical analysis of a questionnaire sent to international students who studied Project Management modules in a Post 92 British University.

\section{Research Methodology}

The research methodology adopted in the current research was selected with the aim of answering the research question described earlier. We are particularly interested in determining the factors, which may affect international students' academic performance in Project Management modules.

To achieve this aim, we chose to design a questionnaire, which would include questions covering as comprehensively as possible the factors believed to impact international students' academic performance. In line with what is described in research methodology literature ([34], [35]) the questionnaire was informed by literature on teaching and learning of international students and the experience of the authors over a number of years as lecturers in the field of project management

The questionnaire methodology was chosen for two reasons: it provides a consistent set of data from a large sample; and more significantly, by retaining anonymity, it allows students to express their concerns honestly, thus maximizing the quality and credibility of the data. The questionnaire was designed in a statement format to capture student opinion. The questionnaire included seventeen statements asking the student (the respondent) to rank the validity of each statement on a scale from one to five ( $1=$ Strongly Disagree, $5=$ Strongly 
Agree). The statements were grouped into the three categories defined earlier in the conceptual framework: (i) Teaching style (ii) English Language and Communication, and (iii) Assessment Methods. Dillman [36] distinguishes between three types of data variables that can be collected through questionnaires: opinion, behaviour and attribute. All of the questions on the questionnaire are of the opinion type.

The questionnaire was sent to international students who previously studied Project Management modules in a Post 92 British University. These students come from a wide range of nationalities and satisfied the "international students" definition presented earlier. The number of questionnaire sent was 300 from which we received 35 responses (Response rate $12 \%$ ). Three questionnaires could not be used because of missing answers to some questions. Therefore, we could only use 32 questionnaires for this study. The research team was very disappointed with the response rate as this prevented if from the use of more sophisticated statistical analysis.

\section{Results}

As mentioned earlier, our aim was to conduct a sophisticated statistical analysis of the questionnaire. However, to our chagrin, the number of replies to our questionnaire received at the time of preparing this paper was not enough to carry out this analysis. Therefore, we have been obliged to conduct a simple analysis in which we calculated some measures of central tendency and dispersion namely mean, median, and standard deviation of the scores associated with each statement in the questionnaire [37]. These measures are presented in Table 1.

The analysis of the results will focus on one category of factors at a time and is based on the values of the three measures represented in Table 1. A high value for the mean and/or the 
median indicates a strong agreement with the statement in the questionnaire. A high value of the standard deviation indicates that individual scores are highly dispersed from the mean.

\section{Category 1: Teaching Style}

The style of lecture presentation by lecturers appears to be a strong factor in helping students understand the subject. This indicates that students do rely heavily on their lecturers' skills in presenting and explaining lecture material. This finding is supported by the fact that the mean score to the opposite statements "The pace of delivery of the teaching is too slow" and "The pace of delivery of the teaching is too fast" are almost identical, although there is more agreement with the latter statement. These two statements clearly indicate that international students have different abilities and strengths, but they all rely on their lecturers' ability to deliver and explain the lecture material to understand the subject.

In addition, international students seem to have some difficulty understanding lectures which are nor well structured, that is lectures in which there is no clear link between its different parts. However, they seem to find the discussions during the class a bit helpful in improving their understanding. Posting information on university learning websites is, to some extent, also helpful in getting the message through to international students.

\section{Category 2: English Language and Communication.}

Students find it easy, to some extent, to express orally their thoughts and to write reports and essays in English Language. In addition, they seem to be quite comfortable reading from Project Management textbooks although they have some difficulties understanding special technical words related to the subject both in lectures and in textbooks. For these reasons, there is quite strong evidence that international students would prefer the subject to be taught in their first language. 


\section{Category 3: Assessment Methods}

Assignments in project management modules appear to be of a reasonable level to international students. This is supported by the fact that students do not find it very difficult to answer exam questions in project management. Opinions are also equally divided regarding the issue of working in group or individual assignments although there is more bias towards preference of group assignments.

Regarding the preferred type of question, there is strong evidence that students prefer assignments with significant mathematical content. This can be related to difficulties in dealing with qualitative questions, which require a higher level of mastery of English language.

\section{Discussion and recommendations}

The results shed light on many issues, which appear to drive the performance of international students. The ability of lecturers to deliver the teaching material at both the right pace and at a suitable depth of explanation is important factors to explain the performance of international students. Given the lack of English language skills of some international students, they tend to rely heavily of lecturers' ability to structure the lecture material and explain it in great detail. This means that lectures should be designed to include a significant volume of information presented in simple and clear language to classes containing a high proportion of international students. Furthermore, international students rely on extra information put by lecturers in web based learning environment when studying the subject. Therefore, lecturers may have to put, on the internet, extra teaching material and more information about academic sources to help international students improve their learning experience. 
The selection of the lecture content and the preparation of the lecture material should take into account the mixture of students' abilities to digest that information. Although classes include a mixture of home and international students with different abilities, it is important that lectures are designed and delivered to suit the mixture of students. Further communication with and advice to vulnerable international students facing specific difficulties can be an excellent medium to bring confidence to these students and help them improve their performance and enjoy the learning experience of project management.

The high requirements of English language to deal with the qualitative part of the project management subject appear to create, to some extent, difficulties for some groups of international students. Some international students may have problems expressing themselves either in written or spoken English. This means that it is important to assess correctly the level of proficiency in English language when recruiting international students and make sure that students are up to the required standards when they come to study in the UK. In addition, it is vital that international students are continuously monitored by lecturers and offered support and given access to English language courses in the university while they are taking their courses.

Although international students appear to be able to read and understand project management textbooks, they find many of the technical words in these textbooks difficult to understand. This may relate to the way technical information is presented in textbooks. This means that textbooks (especially international editions) have to be written in simpler style which suits a large body of students, and lecturers have to look carefully through the books before recommending them to classes including a high proportion of international students.

Regarding assignments, it is unclear from our results whether students prefer group or individual assignments. This may be explained by the fact that international students are not a homogenous group and, therefore, have different abilities and previous learning experiences. 
It is well known that the ability of students to interact with other and their previous experience in teamwork is different depending on the country of origin of the students and the subject they studied before coming to the UK. However, it is clear that it is better if assignments are varied so that some pieces are group based and some are individual based. This would satisfy the different needs of students, but would also enable them to address their weaknesses by forcing students who prefer individual assignments to work in groups, and those who prefer to work in group to develop the skill to work individually.

International students tend to prefer assignments which include a heavy quantitative component. While this is understandable given the difficulties some students may have with English language, it is important that assignments are balanced and cover both the quantitative and qualitative aspects of project management as the assessment strategy must reflect the nature of the subject and cover all areas of knowledge necessary for graduates in this field.

These results have important implications with respect to the teaching of project management modules to international students. With regard to the design and delivery of lectures, it is advisable that lecturers prepare well structured lectures and deliver them in a reasonable pace to allow students the time to understand them. In addition, lecturers should engage international students through class discussions and encourage them to participate in these discussions. Lecturers should also make a good use of the web learning environments, which are becoming a feature of many UK universities these days.

It is necessary to establish that each student possesses the necessary degree of proficiency in English language before accepting them onto the project management module. In addition, it is highly recommended that English Language support continues to be made available to international students during the whole cycle of their studies in the university. The language issue can also be addressed through a careful selection of accompanying text books that are 
not, from a language perspective, very complicated. The process of textbook selection should take into account the simplicity of the style of writing and the ability of international students to get the maximum benefit from reading the textbooks.

Although international students in this study favour assignments with a high proportion of quantitative requirements, there should be a balance of quantitative to qualitative components. The proportion of each component will be different from one module to another, but it is crucial that assignments are designed to be as comprehensive and representative of the course material and its associated learning outcomes as possible. The reluctance of international students to answer qualitative questions should be examined further although it can be partially addressed through the actions described above. One of the aims of assessment is to make sure that all students (international or otherwise) have reached the required academic standards and got the necessary skills to compete in the global job market. This is one of the most important attractive factors of British higher education to international students.

\section{Conclusions}

The aim of this research is to investigate the factors affecting the academic performance of international students in project management. To this end, a framework was developed from the literature and tested empirically through an opinion based questionnaire. Our objective is to identify, from international students' perspective, the factors affecting their performance so that possible corrective actions can be identified in order to improve the learning experience of these students and improve their performance.

The results from the questionnaire regarding the explanatory factors impacting the academic performance of international students are in line with those described in other studies on the subject. The three groups of factors identified in this research are 1) Teaching Style, 2) 
English Language and Communication and 3) assessment methods are consistent with previous research.

There are some limitations to the current research. The most important one is our assumption that international students were a homogenous group whereas, in reality, they come from different regions of the world and, therefore, have different abilities, cultures, and learning experiences.

The size of the sample prevented the authors from carrying out a more sophisticated statistical analysis. The sample was taken only from student in a single university and is not, therefore, representative of students' opinions in other UK universities. In addition, the students in the sample were selected from a business school whereas project management is taught to students in other departments such as engineering and computer science whose students may have different experiences. The study did not specifically differentiate between undergraduate and postgraduate students or between young and mature students. It is expected that further segmentation of our student population along these groups will improve our understanding of the issue of academic performance of international students.

This research is at its infancy. Our research is still on-going and we are in the process of gathering more data in order to get a larger sample, which will allow us to apply a wide range of statistical methods to address some of the sample size related limitations cited above. Moreover, we are planning to build and test a more comprehensive conceptual framework, which will include many of the missed factors in this research such as effects of culture, previous learning methods, and regions from which international students come from.

We believe that little is known regarding many of the issues affecting academic performance of international students in the subject of project management and this require more effort from those involved in the teaching and learning activities in this field. 


\section{References}

[1] Proceedings of the 2nd Project Management Conference: Excellence in Teaching,

Learning and Assessment., Bournemouth University, Bournemouth, UK 2005.

Accessible from http://ibal.bmth.ac.uk/proceedings/. [Last accessed 23rd January, 2008].

[2] Morrison J, Merrick B, Higgs S, Le Metais J. Researching the performance of international students in the UK. Studies in Higher Education 2005:30(3):327-337.

[3] Pauley GF. International-fee-paying students at Curtin University of Technology: a report on their progress after one year. Perth: Curtin University of Technology, 1988.

[4] Cownie F, Addison W. International Students and Language Support: a new survey. Studies in Higher Education 1996; 21(2):221-231.

[5] Abel CF. Academic Success and the International Student: Research and Recommendations. New Directions for Higher Education 2002;117:13-20.

[6] Ryan J. A Guide to Teaching International Students. Oxford: The Oxford Centre for Staff and Learning Development, 2000.

[7] Wu S, Griffiths S, Wisker G, Waller S, Illes K. The Learning Experience of Postgraduate Students: Matching Methods to Aims. Innovations in Education and Teaching International 2001;38(3):292-308.

[8] Biggs J. Teaching for Quality Learning at University. $2^{\text {nd }}$ edn. Maidenhead: The Society for Research into Higher Education and Open University Press, 2003.

[9] Volet S , Renshaw P. Chinese students at an Australian university: continuity and adaptability. In Watkins D and Biggs J (eds). The Chinese Learner; Cultural, Psychological and Contextual Influences. Hong Kong: Centre for Comparative Research in Education/Camberwell, Vic.: Australian Council for Educational Research, 1996.

[10] Mullins G, Quintrell N, Hancock L. The experiences of international and local students at three Australian universities. Higher Education Research and Development 1995;14:201232. 
[11] De Vita G. Inclusive approaches to effective communication and active participation in the multicultural classroom: An international business management context. Active learning in higher education 2000;1(2):168-180.

[12] Ackers J. Evaluating UK courses: the perspectives of the international student, in: D. Mcnamara and R. Harris (eds) International students in higher education: issues in teaching and learning. London: Routledge, 1997.

[13] Bie KN. Norwegian students at British Universities: a case study of the academic performance of foreign students. Scandinavian Journal of Educational Research 1976;20 $(1): 1-24$.

[14] Marshall P, Chilton EHS. Singaporean students in British higher education: the statistics of success. Engineering Science and Education Journal 1995;4(4):155-160.

[15] Williams Sir B. (Eds.). International students in Australia: policy and practice. Canberra: International Development Program of Australian Universities and Colleges, 1989.

[16] Wright T, Cochrane R. Factors influencing successful submission of PhD theses. Studies in Higher Education 2000;25(2):181-195.

[17] Jochems W, Snipppe J, Smid HJ, Verweij, A. The academic progress of foreign students: study achievement and study behaviour. Higher Education 1996;31:325-340.

[18] Makepeac E, Baxter, A. International students and examination failure: a national study. Journal of International Education 1990;1(1):36-48.

[19] Smith YM . Eccles T. An investigation into the learning experience of international students: a pilot study. School of Surveying Occasional Paper no 3, Kingston University, London, UK, 1993.

[20] Fry H .Ketteridge S. Marshall S. (Eds). A Handbook for Teaching and Learning in Higher Education: enhancing academic practice. $2^{\text {nd }}$ edn. London and New York: Routledge Farmer, 2003.

[21] Marton F, Saljo R. On qualitative differences in learning. I. Outcomes and process, British Journal of Educational Psychology 1976;46:4-11. 
[22] Marton F. Saljo R. Approaches to learning in: Marton F. Hounsell D. Entwistle N (Eds). The Experience of Learning. Edinburgh: Scotttish Academic Press, 1997.

[23] Byrne M., Flood B, Willis P. Approaches to Learning of European Business Students. Journal of Further and Higher Education 2002;26(1):19-28.

[24] Cammish NK. Through a glass darkly: problems of studying at advanced level through the medium of English in McNamara D. Harris R (Eds.) International students in higher education: issues in teaching and learning. London and New York: Routledge, 1997.

[25] Todd ES. Supervising international students: problem or opportunity? In McNamara D . Harris R. (eds) International students in higher education: issues in teaching and learning. London: Routledge, 1997.

[26] Cortazzi M . Jin L. Communication for learning across cultures, in McNamara D. Harris R. (Eds.) International students in higher education: issues in teaching and learning. London and New York: Routledge, 1997.

[27] Ridley D. Puzzling experiences in higher education: critical moments for conversation. Studies in Higher Education 2004;29(1):91-107.

[28] Sutherland P, Badger R, White G. How New Students Take Notes at Lectures. Journal of Further and Higher Education 2002;(26)4:377-388.

[29] Mulligan D, Kirkpatrick A. How Much Do They Understand? Lectures, students and comprehension. Higher Education Research \& Development 2000;19(3):311-335.

[30] De Vita G. Cultural Equivalence in the Assessment of Home and International Students: a UK exploratory study. Studies in Higher Education 2002: 27 (2):221-231

[31] Rogriques CA. Culture as a determinant of the importance level business students place on ten teaching/learning techniques: A survey of university students. Journal of Management Development 2005;24(7):608-621.

[32] Jones A. Culture and contexts: critical thinking and student learning in introductory macroeconomics. Studies in Higher Education 2005;30(3):339-354. 
[33] Adams K. Modelling success: enhancing international postgraduate research students' self-efficacy for research seminar presentations. Higher Education Research \& Development 2004; 23 (2):115-130.

[34] Saunders M . Lewis P. Thornhill A. Research Methods for Business Students. $2^{\text {nd }}$ Edn. Harlow: Prentice Hall, 2003.

[35] Hair JF .Babin B . Money AH .Samouel P. Essentials of Business Research Methods. $1^{\text {st }}$ edn. Chichester: Wiley, 2003.

[36] Dillman DA. Mail and Internet Surveys: The Tailored Design Method 2007. $2^{\text {nd }}$ edn, Chichester: Wiley, 2006.

[37] Morris C. Quantitative Approaches in Business Studies. $5^{\text {th }}$ edn. Harlow: Prentice Hall, 2003. 
Table 1: The Mean, Median, and Standard Deviation of the academic performance factors

\begin{tabular}{|c|c|c|c|c|}
\hline & $1=$ Strongly Disagree & Mean & Median & SD \\
\hline & Category 1: Teaching Style & & & \\
\hline 1 & $\begin{array}{l}\text { The way the lecturer speaks is important in understanding the } \\
\text { lecture }\end{array}$ & 3.69 & 4.00 & 1.01 \\
\hline 2 & The pace of delivery of the teaching is too slow & 2.00 & 2.00 & 0.82 \\
\hline 3 & The pace of delivery of the teaching is too fast & 2.25 & 2.50 & 1.00 \\
\hline 4 & $\begin{array}{l}\text { It is difficult to understand what is explained if there is no } \\
\text { clear link between the different parts of the lecture }\end{array}$ & 2.69 & 3.00 & 1.14 \\
\hline 5 & $\begin{array}{l}\text { I find that information put by the lecturer on the module } \\
\text { website always gives the answers to any questions I have after } \\
\text { a lecture }\end{array}$ & 2.63 & 3.00 & 0.89 \\
\hline 6 & I have difficulty with class discussions on project management & 2.19 & 2.00 & 0.91 \\
\hline & Category 2: English Language and Communication & & & \\
\hline 7 & I find reading project management text book difficult & 2.00 & 2.00 & 1.15 \\
\hline 8 & I find writing reports and essays difficult for this module & 2.38 & 2.00 & 1.09 \\
\hline 9 & $\begin{array}{l}\text { The use of some words in project management make it harder } \\
\text { to understand }\end{array}$ & 2.56 & 3.00 & 1.46 \\
\hline 10 & I find it difficult to express my thoughts in spoken English & 2.13 & 2.00 & 1.20 \\
\hline 11 & $\begin{array}{l}\text { I discuss the course material in my first language with my } \\
\text { associates }\end{array}$ & 1.94 & 1.00 & 1.29 \\
\hline \multirow[t]{2}{*}{12} & $\begin{array}{l}\text { I would like to read about project management in my first } \\
\text { language }\end{array}$ & 3.00 & 3.00 & 1.59 \\
\hline & Category 3: Assessment Methods & & & \\
\hline 13 & I find answering examination question difficult in this module & 2.38 & 2.00 & 1.02 \\
\hline 14 & The project management assignment is difficult to understand & 2.25 & 2.50 & 1.00 \\
\hline
\end{tabular}




\begin{tabular}{|c|l|l|l|l|}
\hline 15 & I prefer to work in a teams for assignment work & 2.88 & 3.00 & 1.20 \\
\hline 16 & I prefer to work on my own for assignment work & 2.81 & 3.00 & 1.11 \\
\hline 17 & I am happy with questions which are mathematically based & 3.44 & 3.00 & 1.03 \\
\hline
\end{tabular}


Figure 1: The Academic Performance Conceptual Framework

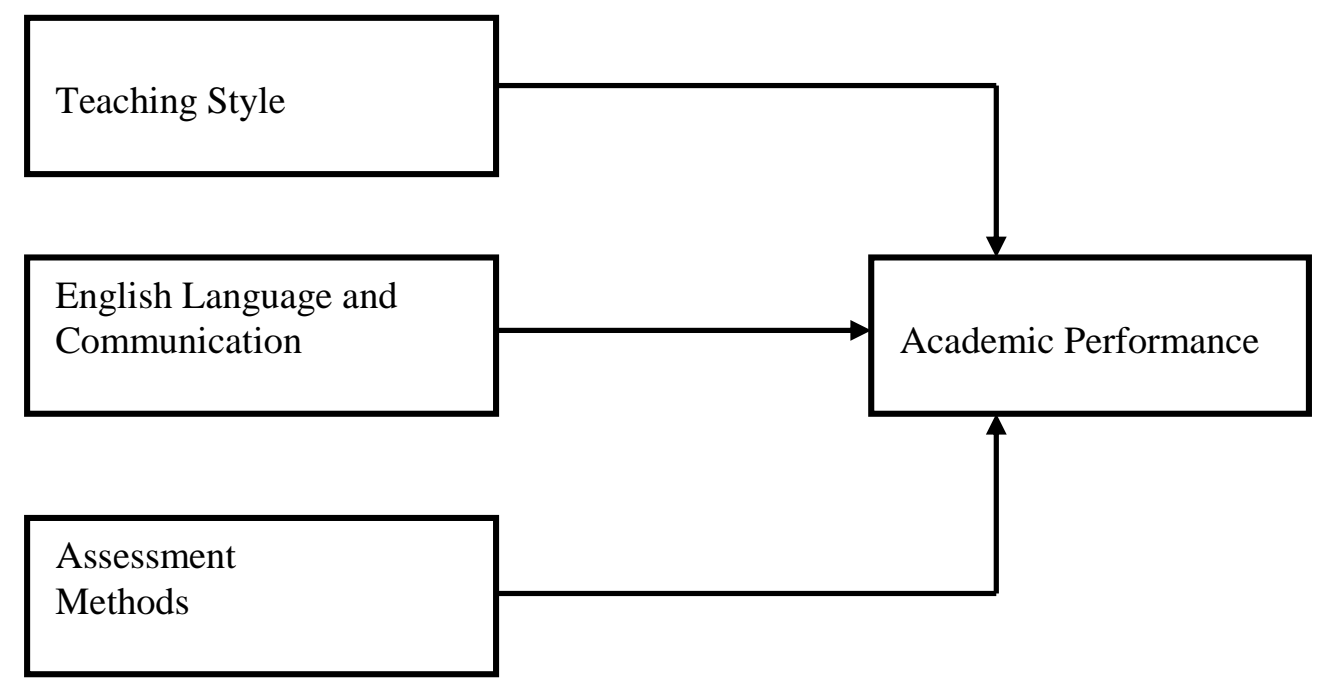

